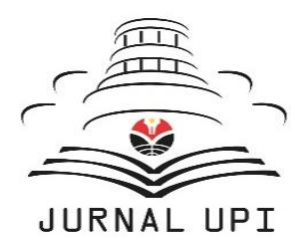

INDONESIAN JOURNAL OF APPLIED LINGUISTICS

Vol. 11 No. 1, May 2021, pp. 49-59

Available online at:

https://ejournal.upi.edu/index.php/IJAL/article/view/34634

https://doi.org/10.17509/ijal.v11i1.34634

\title{
Films for EFL: Exploring the perceptions of a high school teacher
}

\author{
Estefanía Sánchez-Auñón* and Pedro Antonio Férez-Mora \\ Study Program in Education, Department of Didactics of Modern Languages and Their Literatures, Faculty of \\ Education, University of Murcia, Campus Universitario Street, 11, 30100 Murcia, Spain
}

\begin{abstract}
Research on teacher perceptions on the use of films in the secondary school English classroom is scarce since most studies have focused on other educational levels and on the opinions of students. Besides, most of these studies are merely of a theoretical nature. Consequently, there is a need for empirical research which sheds further light on both Compulsory Secondary Education and teacher perceptions on this matter. This study explores the perception of a secondary school teacher on the use of a film as a tool for conducting EFL classes. Data were obtained according to the following steps. Firstly, the English instructor was interviewed regarding her views on the use of authentic audio-visual materials in the English classroom. Then, the teacher examined a film-based lesson plan which included the advantages of authentic audio-visual resources for EFL as defined by experts in the field. Finally, the teacher was interviewed again to trace changes in her perception. The results of the study show that, in the initial interview, the participant's opinion was positive although her use of films as a didactic aid was vague and minimal. However, in the final interview, she reflected a more positive view and she was willing to include films and their multiple educational benefits into her lessons, advocating, therefore, a more holistic understanding of EFL. The contextually situated awareness elicited through the teacher's own experience of the lesson plan made her question her own classroom practice. This led to the amplification of the teacher's understanding of EFL, which, at the post-intervention stage, emerged not only as a linguistic endeavour but also as a platform from where to promote critical thinking, aesthetic sensitivity or awareness towards issues of social justice.
\end{abstract}

Keywords: Authentic audio-visual materials; change in teacher beliefs; films for EFL; innovation in EFL

\begin{tabular}{|c|c|c|}
\hline $\begin{array}{l}\text { First Received: } \\
\text { 10 November } 2020 \\
\text { Final Proof Received: } \\
30 \text { April } 2021\end{array}$ & $\begin{array}{c}\text { Revised: } \\
14 \text { March } 2021\end{array}$ & $\begin{array}{c}\text { Accepted: } \\
\text { 18 April } 2021 \\
\text { Published: } \\
\text { 31 May } 2021\end{array}$ \\
\hline $\begin{array}{l}\text { How to cite (in APA style): } \\
\text { Sánchez-Auñón, E. \& Férez-Mora, } \\
\text { high school teacher. Indonesia } \\
\text { https://doi.org/10.17509/ijal.v1 }\end{array}$ & $\begin{array}{l}\text { A. (2021). Films } \\
\text { ournal of Appliec } \\
1.34634\end{array}$ & $\begin{array}{l}\text { : Exploring the perceptions of a } \\
\text { istics, } 11(1), 49-59 .\end{array}$ \\
\hline
\end{tabular}

\section{INTRODUCTION}

\section{Audio-visual materials and EFL}

Authentic audio-visual materials (films, TV shows, soap operas, documentaries...) have been purported to be greatly beneficial for secondary school English learners and many foreign language teachers are already including them in their lessons (Ruey \& Kun, 2014). Nevertheless, researchers' attention to the cross-fertilization of this kind of videos and EFL classes has been basically of a theoretical nature (Sherman, 2003). Thus, more empirical evidence is needed to prove or disprove the theoretically defined advantages of authentic audio-visual resources (Canning-Wilson, 2000; Willis, 1983). More specifically, concerning the use of films for EFL, the scarce empirical research available has focused on examining student perceptions and performance in university contexts (Charlebois, 2008; Seferoğlu,

\footnotetext{
*Corresponding Author

Email: estefania.sanchez8@um.es
} 
2008; Sturm, 2012), failing to contemplate, therefore, other educational contexts such as compulsory secondary education, where attention to this matter has been minimal and inconclusive since only a very limited number of the advantages of using films for EFL lessons have been tested-Ruey and Kun (2014), for example, devoted their study to analyzing merely secondary school English students' improvement in speaking.

Given its paucity, producing empirical research which focuses on other actors of the teachinglearning process is also necessary. To this end, surveying teachers, specifically their beliefs on the adequacy of conducting English lessons through the thorough use of films might help to consolidate this approach as a sounder and more widespread option when it comes to teaching a FL. Furthermore, the few English instructors who introduce audio-visual materials in their lessons do it far from their full potential because they have not been prepared to do it during their pedagogic training, and authentic audio-visual resources are used as peripheral elements in class rather often, even without any pedagogical objective in mind (Jurkovič \& Mertelj, 2015). In fact, according to Hobbs (2006), English teachers reduce the potential of visual materials as a teaching strategy since they usually take advantage of videos to fill time, keep students entertained, and reward learners' good behavior.

In light of the above-mentioned arguments, it seems necessary to undertake research on teacher beliefs on the use of films, one of the most commonly used types of audio-visual materials, for EFL instruction in high-school settings, a clearly under-researched area as documented above. This is precisely the aim of the present study, and the research question that guides it is: what is the opinion of a high-school teacher on the use of a film as a tool for EFL before and after examining cinema-based EFL lessons?

\section{Benefits of using authentic audio-visual resources for $\mathrm{FL}$}

Leaving aside a small number of isolated pioneering studies such as, for example, Travis (1947), the benefits of the application of audio-visual resources to FL started being contemplated as a viable option during the early 1980s with the emergence of communicative language teaching (CLT) and the development of audiovisual technology (Jurkovič \& Mertelj, 2015). CLT emphasized the importance of meaning and interaction among students to learn an L2 and audiovisual material was held to be a great teaching aid in this respect (Sturm, 2012). However, the intersection between CLT and audiovisual materials did not come without clear challenges. On the one hand, the fact that audio-visual materials involved expensive devices which most high schools, let alone students, could not afford; on the other hand, the need to train teachers in the use of videocassettes since the population in general, and this included teachers, were not accustomed to using them. This implied the emergence of research devoted to instructing teachers on audiovisual skills (Allan, 1985; Lonergan, 1984).

The above described situation regarding the difficulty to get access and handle videocassettes was typical of the 1980s and the early 1990s. Thenceforth the use of authentic videos in the EFL class has increased exponentially for various reasons: the spoken word is replacing the written language; the Internet allows English teachers to use audio-visual resources more easily; legal barriers are disappearing, allowing instructors to download as many videos as they wish (Kaiser, 2011); and cinema, television and technology play a crucial role in students' lives who, growing up in a highly globalized and technologically advanced world, have become digital natives and, therefore, their motivation to learn might depend, to a great extent, on the incorporation of these means into education programs (Berk, 2009; Tafani, 2009).

Apart from those previously specified, one especially important reason underlying nowadays easy access to audiovisual materials, including films, has to do, no doubt, with the worldwide consolidation of the Internet (Hortiguiela-Alcalá et al., 2019). On the Internet, the population in general, and EFL teachers in particular, can screen, produce and disseminate audiovisual materials from a plethora of new formats. These include, to mention just a few of the available possibilities, WhatsApp, Telegram, Instagram, YouTube, TikTok, or Zoom; online platforms (HBO or Netflix, for example); or learning management systems such as Moodle, Genially and virtual classroom software at specific high schools and universities.

Given the prominence with which existing research advocates the inclusion of audiovisual material in FL, below, the authors of the study will present an in-depth exploration of the specific benefits that such a crossfertilization is said to bring about. These benefits fall within three major dimensions: the linguistic dimension, the inter/cultural dimension and the motivation dimension.

\section{The linguistic dimension}

EFL learners can develop their linguistic competence due to constant exposure to authentic videos. Several scholars (Allan, 1985; CanningWilson, 2000; Fernández-Guerra, 2013; Kaiser, 2011; Lonergan, 1984; Ruey \& Kun, 2014; Tomalin, 1986) have shown that, if English students work with audio-visual materials, they enhance their listening, reading and oral skills, as well as their knowledge on English grammar, vocabulary and pragmatics.

Authentic videos help EFL learners to improve their listening skills because they display 
paralinguistic information such as L2 speakers' gestures, facial expressions, and postures which help students grasp the speakers' messages (Sherman, 2003; Yassaei, 2012). Besides, in accordance with Stewart (2006), subtitled films help EFL students practice their reading skills, as long as both the film and the subtitles are in English. English students need to read the speakers' words quickly in order to understand the film and, therefore, they get used to reading faster, thus enhancing their reading ability. Added to listening and reading skills, secondary school learners are encouraged to practice their speaking ability when watching a video because they see plots which arouse their curiosity, and every student is eager to share their views at the end of any video (Allan, 1985; Lonergan, 1984; Tomalin, 1986). Even introverted English students begin interacting with their classmates and practicing their oral skills because film scripts are models which they can imitate (Lonergan, 1984; Stewart, 2006). In turn, EFL learners may improve more specific features of their speaking ability such as pronunciation, intonation and stress because films show accurate and realistic samples of the different varieties of the English language which they can reproduce afterwards (Kaiser, 2011).

Apart from the English language skills, audiovisual materials have been shown to be highly practical in order to teach grammar, vocabulary and pragmatics because they provide learners with a large amount of authentic L2 input (Lonergan, 1984). As authentic videos like films typically show daily-life events, students can learn how grammatical structures are used in day-to-day situations. Therefore, they learn how to use them idiomatically with the help of visual clues (Lonergan, 1984; Polio, 2014). Moreover, students also see how different lexical items are used in a realistic situation, which facilitates intake and memorization (Alwehaibi, 2015; Lonergan, 1984). Through the authentic examples provided by films, EFL speakers can learn what kind of formulaic expressions and structures are frequently used in everyday routines such as ordering food in a restaurant. Hence, EFL learners also master English pragmatic issues while learning grammar and vocabulary.

\section{The inter/cultural dimension}

Many studies devoted to examining EFL teaching (Seferoğlu, 2008; Stevenson, 2013; Sturm, 2012; Yunus et al., 2013) have suggested that authentic audio-visual resources provide L2 learners with countless opportunities to learn about culture and enhance their intercultural awareness, as discussed below. Authentic videos such as a film or a soap opera show students L2 speakers' lifestyle, which teachers cannot illustrate just orally. Thus, students learn about everyday situations, including how English people coexist, their day-to-day routines and their workplaces (Allan, 1985; Pisarenko, 2017; Salas, 2002; Seferoğlu, 2008; Sturm, 2012; Tomalin, 1986; Yunus et al., 2013). Besides, according to Bueno (2009), a film can even reflect the values and the ideological system of the period in which it is set. Indeed, authentic videos portray culture-specific attitudes and behaviors such as eye contact, proximity, symbols, and gestures (Allan, 1985; Tomalin, 1986; Willis, 1983), which students need to know in order to avoid embarrassing misunderstandings and cultural conflicts (Tomalin, 1986).

Likewise, this cultural background leads students to compare the L2 culture with their own cultural system, analyzing similarities and differences between them. Consequently, English students may get a deeper understanding of their own culture and improve their intercultural awareness by watching a film (Kaiser, 2011; Sturm, 2012).

\section{The motivation dimension}

Alwehaibi (2015), Berk (2009), Chen and Li (2011), Harness and Drossman (2011), Salas (2002), and Tafani (2009) have highlighted that authentic audiovisual resources are extremely motivating for students for multiple reasons which are going to be illustrated hereunder: (i) learners experience aesthetic pleasure; (ii) they learn to cope with emotions; (iii) they are exposed to realistic language; (iv) learners enhance their creative and critical thinking skills; (v) this kind of materials is a source of non-trivial topics; and (vi), students may even be requested film scripts they themselves have developed. One of the reasons why authentic audio-visual resources promote students' motivation is because secondary school English learners can experience aesthetic pleasure due to the visual impact of videos. Students become more active and friendlier L2 learners when they watch a film because they take much pleasure in contemplating engaging images in class, and this aesthetic delight reduces their anxiety (Stevenson, 2013). Furthermore, authentic videos help students to deal with emotions and feelings. When students watch a film, they can scrutinize the characters' reactions to certain events and, therefore, they can learn to identify and understand other people's feelings (Kaiser, 2011). Furthermore, these materials prompt learners' reactions and elicit students' emotional responses such as excitement, anger, and laughter, thus helping high school English students to express their own feelings (Berk, 2009; Jurkovič \& Mertelj, 2015).

Another reason whereby the didactic implementation of authentic videos is so motivating is because they depict realistic language. The language which students learn from EFL textbooks is simplified and adapted for pedagogical purposes and, therefore, artificial and unrealistic (Fernández- 
Guerra, 2013; Salas, 2002). By contrast, authentic videos show realistic samples of the English language: they reflect the day-to-day use of English in a wide range of contexts and complex communicative situations in which students may be involved when they are in L2 contexts (Alwehaibi, 2015; Lonergan, 1984; Travis, 1947).

Authentic videos also promote students' creative skills, which is highly stimulating for compulsory secondary education learners. Visualaids are a limitless source of appealing tasks in which high school English learners are allowed to work creatively. For example, "freeze framing" is an activity in which foreign language learners predict further details about the characters of a video (Çakir, 2006). Moreover, authentic videos provide high school students with many opportunities to enhance their creative skills because they foster brainstorming, an exercise which allows learners to free their imagination and express what they want with regard to the videos they watch (Berk, 2009).

Many researchers have attested that English learners can also develop their critical thinking skills when they work with authentic audio-visual resources in the EFL classroom because they foster active viewing and the development of personal ideas. As noted by Allan (1985), our minds are more engaged when we have to fill an information gap, and, since students are usually asked to do some follow-up tasks after watching a video, they are cognitively active and engaged. Besides, the visual impact of videos promotes high-order thinking skills in that students make predictions and speculate for plot based on the imagery they receive (CanningWilson, 2000). Additionally, Stewart (2006) claimed that, as films portray controversial matters, they encourage English learners to examine the world around them and develop their own views on what they see. In fact, these enhanced critical thinking skills can be transferred from the classroom to the students' daily lives, therefore becoming more demanding analytical citizens (Lonergan, 1985; Tafani, 2009). Pisarenko (2017) regards this latter aspect as essential for learners' personal growth. Charlebois (2008) demonstrated the consciousnessraising potential of films in that their students reflected on race and sexuality at the same time as they learnt English when watching the film The Color Purple.

Another feature which makes authentic videos so encouraging for foreign language learners is that they are a source of non-trivial topics. Films increase secondary school English students' motivation because they depict key issues that give rise to discussion among learners (Sturm, 2012). As suggested by Kaiser (2006), working with films which deal with social matters such as homosexuality, racism and sexism might help teenage learners develop as highly committed future citizens and members of a community.
Lastly, audio-visual materials are a motivating pedagogical tool because they allow teachers to design varied tasks which are closer to the students' reality. Apart from watching and working on films in the classroom (asynchronous exploitation), cinema may also be used synchronically. That is, students may be asked to produce short films themselves into which they incorporate the contents covered in their English lessons. Filmmaking for educational purposes has been shown to have a positive impact on students' learning and motivation levels, as reported by Chen and $\mathrm{Li}$ (2011) and Harness and Drossman (2011). For instance, Chen and $\mathrm{Li}$ explained that the EFL students who participated in their study stated that, despite requiring much time and effort, filmmaking was not only fun but also very helpful for improving their English, especially their speaking.

In order to make filmmaking even more stimulating, students can be asked to upload their films to Internet platforms and social networks they are familiar with such as YouTube, Instagram, Facebook, TikTok, Snapchat, or Stickam, where they can share their opinions and provide each other with feedback. As digital natives, this film-based task is stimulating for students because it connects EFL lessons with their daily experiences. As a matter of fact, multiple scholars have demonstrated that using these technological and online resources does motivate students (Hortigüela-Alcalá et al., 2019; Montoneri, 2015).

\section{METHOD \\ Respondents}

The data of the study were gathered from an EFL teacher who worked at a high school in southeast Spain where she taught Grades 1 and 4 of compulsory secondary education. She had a degree in English Studies and a master's in TESOL. Although she was a native speaker of Spanish, her level of English was C2 according to the European Framework of Languages. The participant had 15 years of experience teaching EFL and had always been interested in refining her pedagogical skills since she often took training courses, besides being engaged in an Erasmus project with her high school.

\section{Instruments}

The teacher's views were elicited through two semistructured interviews - an initial interview (Appendix A) and a post-reflection interview (Appendix B). This method was chosen because it allowed us to modify the script during the process itself so that we could include extra questions aimed at targeting interesting points which the teacher might bring about and which the authors had not contemplated when defining the questions in the first place. 


\section{Procedures}

The research adopted a case study approach which consisted of the thorough analysis of one teacher's views on the pedagogical exploitation of a film for EFL.

The initial interview consisted of four main questions about the teacher's practices concerning the use of authentic audio-visual materials in the EFL classroom. These four questions allowed the authors to examine her opinions on the exploitation of films for didactic purposes and analyze her background knowledge on this topic.

Following the careful examination of the data obtained from the initial interview, the authors designed a lesson plan (Appendix C) based on Ben $X$, a film directed by Nic Balthazar and produced by Peter Bouckaert (2007). The abovementioned film was chosen because it had few characters and it was easily and clearly structured. Furthermore, the film was about a content, bullying, which students might find relevant for their everyday life and from which instructors could design interesting language exercises. Still, what made us finally opt for this film was its depiction of bullying, an issue which is increasingly present in secondary school classrooms.

In line with the recommendations of several experts in the field (Allan, 1985; Lonergan, 1984; Tomalin, 1986), the film Ben $X$ was exploited as follows. In order to design the cinema-based lessons, the authors of this paper selected several relevant fragments which lasted about 5 minutes. Thus, instead of playing the whole film, as most teachers wrongly do (Hobbs, 2006), only those fundamental excerpts were used as class material. In this manner, we could (i) direct the learners' attention to the contents the lessons targeted, especially bullying; and (ii) have sufficient time to cover those contents (see Appendix $\mathrm{C}$ for a list of contents). As suggested by Sherman (2003), the rest of the plot was narrated by the teacher so that students could get a holistic idea of the film and did not feel there was a fragmentary exploitation of the film. Students were also encouraged to watch the film at home in case they needed to check any aspect they might have missed during the lessons, or simply for pleasure.

This cinema-based lesson plan was designed at a B1 level of English and, therefore, it could be implemented in Grade 4 of compulsory secondary education, a class the teacher was in charge of at the time of the interviews.

Afterwards, the teacher was given three days so that she could analyze the lesson plan before the final interview. During the interview, which lasted an hour, the questions were aimed at encouraging the teacher to reflect in depth on the alleged advantages of using films for EFL, even directing her attention to specific activities if that was necessary to clarify unclear aspects.

\begin{abstract}
Data analysis
The two interviews were recorded and transcribed and the data obtained coded, compared and analyzed by both researchers to identify patterns in the teacher's answers from which to answer the research question.
\end{abstract}

\section{FINDINGS AND DISCUSSION}

The research question which guides this study is what the perceptions of a high school teacher were on the use of a film as a tool for EFL before and after examining a lesson plan in which the benefits of cinema-based EFL lessons had been included. The answer to this research question will be examined below according to the teacher's answers at the pre and post reflection stages.

\section{The teacher's views before examining the lesson plan}

In the initial interview, the teacher showed a positive attitude towards the use of authentic audiovisual resources in EFL programs. The teacher stated that she occasionally played subtitled films and TV series in their original version:

Yes, I use them [authentic videos] some times. Above all, TV series in English with English subtitles. Sometimes, I also play films, but I prefer using TV series due to time constraints. Exposition to audiovisual materials is quite useful for enhancing learners' listening and reading comprehension. When I use films, I do so as an enjoyable way of breaking with the routine of the textbook and I ask students to write a summary of the plot.

From the above-mentioned quotation, it is clear that the participant made a very limited use of the potential of audiovisual materials in her classes, merely focusing on some of the prospective linguistic benefits they might have on her students and without a clear awareness of how to take advantage of the wide array of pedagogical possibilities of this textual modality. It is interesting to note that the teacher seemed to develop an increasing awareness that her use of films could be enhanced. In fact, she pointed out a limiting factor which seemed to impact on her teaching practice: her own teachers did not use authentic audiovisual resources. As she put it:

When I was studying, my teachers rarely used audiovisual material in their lessons, even at University. I guess that they avoided the use of authentic audiovisual resources owing to the lack of resources at that time such as the Internet and technological devices like computers and projectors, which are essential in order to make use of films in class.

The teacher's views after examining the lesson plan 
As shown in the previous section, the research participant had an initial positive position as regards the didactic use of films. Nevertheless, she did not exploit them to their full potential due to the influence of her previous education and because her understanding of audio-visual materials was limited to improving students' listening and speaking skills, thus, failing to address other linguistic benefits, not to mention inter/cultural and motivational advantages.

The data derived from the final interview revealed that the teacher's views changed after examining the film-based lesson plan. In fact, she highlighted that the experience had been an eyeopener for her as she unearthed various engaging applications of films, which will be discussed by dimensions below.

\section{The linguistic dimension}

Concerning language skills, the instructor confirmed the utility of films for students to practice their listening and speaking ability, something she had already acknowledged in the initial interview. In line with Kaiser (2011), she specifically asserted that high school learners can get used to listening to different English accents when they watch a film. As for English oral skills, the research participant referred to several features of films which have been purported by experts in the field. The instructor assured that EFL students can learn how to pronounce some English words when watching a film (Kaiser, 2011), and that learners enhance their speaking ability because, usually, they are actively involved in debates on films (Allan, 1985; Lonergan, 1984; Tomalin, 1986). Indeed, the interviewee stated that she had liked "audio dubbing," one of the activities included in the didactic unit designed (see appendix C, stage 1, activity 3):

By the way, I liked this activity a lot [audio dubbing]. I reckon that it is quite interesting because, apart from speaking, students can listen to themselves afterwards and become aware of their own mistakes. Besides, they will find it amusing.

In the first interview, the teacher emphasized the use of authentic videos in order to improve students' reading comprehension. However, she took a negative position as regards the usage of films to enhance reading skills in the second one:

It is true that most students need to read the subtitles in order to comprehend the plot of any given film, so they can improve their reading ability, but I think it is not sufficient. In my opinion, learners must read not only the script of a film but also other types of texts such as articles, reviews, books...

After listening to the English instructor's view, the authors showed her a task of the lesson plan in order to exemplify how films could also be exploited to enhance high school learners' reading skills. In this exercise (see appendix C, stage 3, activity 2), students were asked to look for information about bullying in order to do an oral presentation, so they needed to read different types of texts such as research articles and newspapers so as to do the task properly. The participant examined the activity and, afterwards, she reflected a more positive opinion:

Right, I can see more reading comprehension in this exercise and it could really help students, but I still think that learners should be asked to do more activities about texts.

Concerning the use of films for enhancing EFL learners' knowledge of grammar, the instructor did not mention anything about it in the first interview. However, in the final interview she discovered this advantage of films due to the questions she was asked. The participant of the study was ambivalent about the usefulness of films to teach grammatical structures:

No... I do not think that films are helpful to learn grammar. I have seen that you include explanations and activities to practice verb tenses, but a film or a TV series is not enough for students to really understand grammar patterns. Only learners with a high level of English would be able to learn grammar by watching a film.

However, scholarly research has demonstrated that constant exposure to films does help EFL students to learn about English grammar for various reasons. Lonergan (1984) alleges that the visual support provided by authentic videos makes it easier for students to understand complex language structures as they can examine paralinguistic cues. Besides, this kind of resource allows learners to see how grammar patterns are used in everyday situations, so they can learn how to produce them more idiomatically (Polio, 2014). Moreover, the cinema-based lesson plan evidenced that, apart from simply playing a film and allowing students to watch it, secondary school English instructors may take advantage of that input in order to teach linguistic rules more explicitly and in a contextualized way. In this respect, the lesson plan focused on some clips from the film from which some explanations about complex grammar contents as well as activities to practice them were derived (see appendix C, stage 1, activities 4 and 5). This provided learners who had a low level of English with more opportunities to understand the contents. Conversely, the interviewee agreed with Salas (2002) and Tabatabaei and Gahroei (2011) because she remarked the effectiveness of films when it came to the acquisition of new lexical items. Specifically, she alleged that students can learn a wide range of words when watching films, particularly, informal lexicon which is not typically portrayed in EFL textbooks. 
As scrutinized before, the teacher's perception on the linguistic benefits of using a film for EFL was more positive and amplified in the final interview as compared to the initial interview. Nonetheless, it is for the inter/cultural and the motivation dimensions where the greatest changes in the teacher's view on the use of films were documented since she did not mention any cultural and motivational advantage of cinema in the initial interview, becoming aware of such benefits after examining the lesson plan.

\section{The inter/cultural dimension}

In the final interview, the participant's attention was directed to a task which fostered students' inter/cultural awareness (see appendix C, stage 3, activity 1 ), and she provided a very positive opinion on this benefit of films. In agreement with the multiple scholars who have focused on this key aspect (Allan, 1985; Pisarenko, 2017; Salas, 2002; Seferoğlu, 2008; Sturm, 2012; Tomalin, 1986; Yunus et al., 2013), the interviewee asserted that films help secondary school students to increase their knowledge of English-speaking cultures as they depict characteristic lifestyles, attitudes and the day-to-day routine of speakers. Besides, the teacher remarked that films motivate EFL learners to discover the target culture much more than traditional materials:

There are some textbooks which deal with the English culture, for instance, the one called Mosaic which we use with bilingual groups. However, I reckon that students are not motivated to know about the target culture in such a way, they find it boring, so they usually learn little about it. I think that they are more encouraged to know about the English society when they are shown how it really is in a film.

\section{The motivation dimension}

In the final interview the research participant also became aware of the motivation dimension of cinema owing to the lesson plan. Indeed, she emphasized the aesthetic pleasure that high school learners might experience due to this type of materials. As underlined by Allan (1985), Alwehaibi (2015), Stevenson (2013), and Tomalin (1986), the English instructor asserted that students take much delight in watching authentic videos in that "All students without exception enjoy it a lot when I play a film or a TV series." Furthermore, the interviewee confirmed the fact that films reflect authentic samples of the foreign language. The teacher was in tune with Alwehaibi (2015), Lonergan (1984), and Travis (1947) because, in the post-reflection interview, she claimed that films show examples of the English language which are far more realistic than those included in textbooks as they portray everyday language.

In the lesson plan based on Ben $X$, there were several activities which promoted EFL learners' high-order thinking skills. For example, a task in which students were asked to reflect upon the meaning of "game over" in the film and a debate on bullying in which they supported their views on the topic (see appendix C, stage 1, activities 6 and 7). In this case, the research participant was congruent with Stewart (2006) since, as he argues in his empirical study, the teacher surveyed asserted that films encouraged secondary school English students to think critically and develop their own opinions due to the display of controversial issues. Likewise, the English teacher endorsed the exploitation of films to foster students' creative skills. She even admitted the fact that creative skills were usually forgotten in the EFL classroom on the grounds that instructors devote too much time to the teaching of grammar patterns and lexical items. Moreover, when the interviewee was asked to state which advantages of cinema would be more stimulating and helpful to the students, she replied:

I reckon that students would enjoy very much practicing their critical thinking and creative skills. I must say that I am amazed by this way of working with films because I think that learners would love it.

In line with Sturm (2012), the research participant also confirmed in the final interview that one of the reasons why films are motivating is that they exhibit non-trivial topics. She specifically referred to the fact that Ben $\mathrm{X}$ revolved around the topic of school bullying, which students might consider relevant and attractive because it might help them raise their awareness on this key social issue. Regarding the didactic application of films to teach EFL learners to cope with emotions, the interviewee was doubtful at first on the grounds that films might help older secondary school students to understand feelings but, from her point of view, students in the 1st and 2nd year of Compulsory Secondary Education were still too young to pay attention to those details. To challenge this perception, the authors discussed with the teacher two activities from the lesson plan which dealt with emotions. In one of them (see appendix C, stage 1, activity 4), students were required to describe how the main character of the film was feeling in a particular scene - in that moment, Ben is devastated and embarrassed because he has just been bullied. After explaining the task to the teacher, she started to see it in a new light and reflected a more positive view:

Yes, you are right. The activity in which students have to describe Ben's emotions is very explicit because they are directly asked to analyze his feelings, so it may be a suitable exercise for the younger learners too.

In light of the results and the discussion undertaken thus far, it can be stated that the examination of the lesson plan made the English instructor see that, as shown in the final interview, 
using cinema for EFL lessons had many more advantages than those she had mentioned in the initial interview. Whereas in the first interview the teacher considered cinema just useful for students' listening and speaking skills, her opinion in the postintervention interview went on to include inter/cultural and motivational benefits. This evolution is made clearer in the following quotation in which the teacher reacted to the question on whether her analysis of the film-based teaching unit had helped her change her view towards the use of cinema for EFL:

Yes, my view on the use of films has changed because I did not know that English teachers could take so much advantage of films. I must say that I was really impressed when I examined the teaching unit. I love some of the tasks you have shown me, particularly, audio dubbing, the activity in which students are asked to create a character, thought channel, and the alternative ending.

Besides, at the end of the final interview, the English instructor declared that, from then onwards, she was going to use films for more than listening and speaking activities and as often as possible. The teacher asserted that she would like to promote, especially, students' inter/cultural awareness, their understanding of emotions and feelings, their critical thinking and their creative skills. In fact, she even mentioned that, with the permission of the authors, she was going to incorporate some of the tasks included in the lesson plan into her future teaching.

Finally, it is also worth noting that, in spite of her initial enthusiasm, the EFL teacher was less positive when explaining how her workmates in the English department might welcome cinema-based lessons:

There are several English teachers who develop creative projects, so I think that they would be delighted to try this way of working with videos. However, there are also teachers who would not accept it because they have been teaching in the same way for many years, so they tend to be reluctant to change. On the whole, I think that encouraging all the English teachers of the department to exploit films in this manner will be very difficult.

Hence, while the interviewee herself was convinced of the educational benefits of cinema for EFL students, she felt that convincing the other teachers to follow her was the most complex assignment. The instructor attributed the low use of films to time constraints, the different backgrounds of secondary school students and the lack of flexibility owing to the syllabus and the criteria established by the department.

\section{CONCLUSION}

This study aimed to tap into the perception of a high-school teacher on the use of a film as a tool for
EFL before and after examining a film-based lesson plan. In the final interview, the teacher came to have a much more positive and holistic view on the use of films as a didactic tool for the English class: from playing a film to merely request from students a written summary, as reported in the initial interview, to acknowledging the potential of cinematic discourse to cover not only the whole spectrum of linguistic advantages, but, especially, to raise students' awareness on inter/cultural, emotional, and aspects related to social justice.

Encouraging the teacher who participated in our study to reflect on a cinema-based lesson plan made her question her own classroom practice, which, in turn, might have a positive impact on students' language learning processes and personal growth. This seems to highlight the potential of eliciting pedagogical reflection from teaching sequences to induce change in teachers. However, promoting such change is a challenging task since, not until seeing a positive evolution in students' learning will instructors start to modify their teaching strategies - teachers' behaviour is not usually in line with their beliefs (Dörnyei, et al., 2016). Apart from the lack of training, other factors which might prevent EFL instructors from using films in their lessons are time constraints, lack of didactic cinema-based examples, and teacher adherence to merely instrumental approaches to EFL where the focus of the instruction is merely on acquiring linguistic competence.

This study is based on the opinions of a single teacher and, consequently, the generalization of the results obtained is unfeasible. However, the positive change reported in the teacher's attitude towards using films for EFL, together with the paucity of empirical data exploring the intersection between cinema and FL, makes the examination of such an intersection a line of enquiry worth of further consideration. Firstly, quantitative and qualitative studies with larger numbers of participants should be conducted in order to get reliable and generalizable data. Secondly, lesson plans based on films should be implemented in high school English lessons to check the extent to which students find them helpful for their EFL learning. Finally, more studies should also be conducted to check students' perceptions on the use of films in the English class as compared with those by teachers.

\section{REFERENCES}

Allan, M. (1985). Teaching English with video. Longman.

Alwehaibi, H. O. (2015). The impact of using YouTube in EFL classroom on enhancing EFL students content learning. Journal of College Teaching \& Learning (TLC), 12(2), 121-126. https://doi.org/10.19030/tlc.v12i2.9182 
Balzathar, N. (Director) \& Bouckaert, P. (Producer) (2007). Ben X [Motion picture]. Deutsche Filmvertriebs (DFV).

Berk, R. A. (2009). Multimedia teaching with video clips: TV, movies, YouTube, and mtvU in the college classroom. International Journal of Technology in Teaching and Learning, 5(1), 121. https://sicet.org/main/wpcontent/uploads/2016/11/ijttl-09-011_Berk.pdf

Bueno, K. A. (2009). Got film? Is it a readily accessible window to the target language and culture for your students? Foreign Language Annals, 42(2), 318- 339. https://doi.org/10.1111/j.19449720.2009.01023.x

Çakir, I. (2006). The use of video as an audio-visual material in foreign language teaching classrooms. TOJET: The Turkish Online Journal of Educational Technology, 5(4), 6772. http://www.tojet.net/articles/v5i4/549.pdf

Canning-Wilson, C. (2000). Practical aspects of using video in the foreign language classroom. The Internet TESL Journal, 6(11). Retrieved March 10, 2018, from http://iteslj.org/Articles/Canning-Video.html

Charlebois, J. (2008). Developing critical consciousness through film. TESL Canada Journal, 25(2), 124-132. https://doi.org/10.18806/tesl.v26i1.133

Chen, C., \& Li, K. (2011). Action to acquisitionboost students' English learning motivation with a filmmaking project. Journal of Educational Technology Development and Exchange, 4(1), 71-80. https://doi.org/10.18785/jetde.0401.06

Dörnyei, Z., Henry, A., \& Muir, C. (2016). Motivational currents in language learning: frameworks for focused interventions. Routledge.

Fernández-Guerra, A. (2013). Using TV series as input source of refusals in the classroom. In $\mathrm{P}$. Salazar-Campillo \& O. Martí Arnàndiz, (Eds.), Refusals in instructional contexts and beyond (pp. 5-23). Brill Academic Publishers. https://doi.org/10.1163/9789401209717_003

Harness, H., \& Drossman, H. (2011). The Environmental education through filmmaking project. Environmental Education Research, 17(6), 829-849. https://doi.org/10.1080/13504622.2011.6186 26

Hobbs, R. (2006). Non-optimal uses of video in the classroom. Learning, Media and Technology, 31(1), 35-50. https://doi.org/10.1080/17439880500515457

Hortigüela-Alcalá, D., Sánchez-Santamaría, J., Pérez-Pueyo, A., \& Abella-García, V. (2019). Social networks to promote motivation and learning in higher education from the students' perspective. Innovations in Education and Teaching International, 56(4), 412-422.

https://doi.org/10.1080/14703297.2019.1579 665

Jurkovič, V., \& Mertelj, D. (2015). Pedagogical uses of authentic video in ESP classrooms for developing language skills and enriching vocabulary. Scripta Manent, 9(2), 15-33. https://scriptamanent.sdutsj.edus.si/ScriptaM anent/article/view/126/112

Kaiser, M. (2011). New approaches to exploiting film in the foreign language classroom. L2 Journal, 3(2), 232-249. https://doi.org/10.5070/L23210005

Lonergan, J. (1984). Video in language teaching. Cambridge University Press.

Montoneri, B. (2015). Impact of students' participation to a Facebook group on their motivation and scores and on teacher's evaluation. IAFOR Journal of Education, 3(1), 61-74. https://files.eric.ed.gov/fulltext/EJ1100572.pdf

Pisarenko, V. (2017). Teaching a foreign language using videos. Social Sciences, 6(4), 125-146. https://doi.org/10.3390/socsci6040125

Polio, C. (2014). Using authentic materials in the beginning language classroom. CLEAR Michigan State University, 18(1), 1-8. http://clear.web.cal.msu.edu/wpcontent/uploads/sites/22/2018/10/2014Spring.pdf

Ruey, S., \& Kun, L. (2014). Using films to teach speaking in the ESL classroom: A case study. UNISEL Journal of Social Sciences and Humanities, 1(1), 50-56.

Salas, M. M. R. (2002). Selecting appropriate authentic video material for an EFL classroom. Repertorio Americano, 13-14, 311-322.

Seferoğlu, G. (2008). Using feature films in language classes. Educational Studies, 34(1), $1-9$. https://doi.org/10.1080/03055690701785202

Sherman, J. (2003). Using authentic video in the language classroom. Cambridge University Press.

Stevenson, S. (2013). Attitudes toward, and usage of authentic media in secondary foreign-language classes in Polk County, Florida [Unpublished thesis]. Faculty of the School of Education, Florida Southern College.

Stewart, D. M. (2006). Film English: Using films to teach English. Electronic Journal of English Education, 24, 1-17.

http://english.ncu.edu.tw/Stewart/Research/Fil m\%20English.pdf

Sturm, J. L. (2012). Using film in the L2 classroom: A graduate course in film pedagogy. Foreign Language Annals, 45(2), 246-259. 
https://doi.org/10.1111/j.1944-

9720.2012.01187.x

Tabatabaei, O., \& Gahroei, F. R. (2011). The contribution of movie clips to idiom learning improvement of Iranian EFL learners. Theory and Practice in Language Studies, 1(8), 9901000. https://doi.org/10.4304/tpls.1.8.990-1000

Tafani, V. (2009). Teaching English through mass media. Acta Didactica Napocensia, 2(1), 8195. https://www.learntechlib.org/p/158961/

Tomalin, B. (1986). Video, TV and radio in the English class: An introductory guide. Macmillan.

Travis, J. E. (1947). The use of the film in language teaching and learning. ELT Journal, 1(6), 145149. https://doi.org/10.1093/elt/1.6.145

Willis, D. (1983). The potential and limitations of video. In J. McGovern (Ed.). Video applications in English language teaching (pp.17-27). Pergamum Press.

Willis, J. (1983). The role of the visual element in spoken discourse: Implications for the exploitation of video in the EFL classroom. In J. McGovern (Ed.) Video applications in English language teaching (pp. 29-42). Pergamum Press.

Yassaei, S. (2012). Using original video and sound effects to teach English. English Teaching Forum, 50(1), 12-16.

Yunus, M. M., Salehi, H., \& John, D. S. A. (2013). Using visual aids as a motivational tool in enhancing students interest in reading literary texts. Recent Advances in Educational Technologies, 2, 114-117. https://arxiv.org/ftp/arxiv/papers/1305/1305.63 60.pdf

\section{Appendix A: initial interview}

\section{APPENDICES}

1. Do you use authentic audio-visual materials (films, TV series, video clips...) in your English lessons?

2. If you answered yes to the previous question, explain the reasons whereby you use authentic audiovisual resources, how you do it and how often you use these materials.

3. If you answered no to the first question, explain the reasons whereby you do not use authentic audiovisual materials in your lessons.

4. Do you remember if your English teachers at primary school, secondary school or university used authentic audio-visual content in their lessons? If they did, how did they use it? And if they did not, why do you think they did not make use of authentic videos?

\section{Appendix B: final interview}

1. What do you think about the use of authentic audio-visual resources to improve students' linguistic competence as shown in this didactic unit? Do you think it helps students? This includes listening, reading and speaking skills as well as the learning of grammar and vocabulary.

2. What's your view on the use of films so as to foster students' intercultural awareness as shown in these cinema-based lessons? Do you think films are useful to achieve this?

3. What about the motivation dimension? Do you agree with the fact that films motivate students to learn English? Do you think that this didactic unit is stimulating for EFL learners?

4. Do these lessons help students to understand emotions and feelings?

5. These film-based tasks are intended to promote students' critical thinking and creative skills. Do you think they do? Would you say that films help learners to enhance these skills?

6. As discussed by various researchers, students experience aesthetic pleasure when watching films, do you agree with this statement?

7. Films are said to depict realistic language; do you think so?

8. According to several scholars, films are motivating since they portray non- trivial topics. What do you think about that?

9. After knowing about the educational benefits of authentic audio-visual materials like films and analysing some lessons based on a film, has your view on the use of cinema in EFL changed?

10. Would you use films in a different way henceforth?

11. Which advantages would you like to put into practice? Which ones do you think students would enjoy the most?

12. Why do you think that EFL teachers do not use films in this way?

13. Do you think that your workmates would accept following this cinema-based approach to EFL? Why/why not? 


\section{Appendix C: summary of the cinema-based lesson plan (Ben X)}

Contents of the lesson plan

- Linguistic contents: the present perfect; vocabulary about feelings; modals of ability; should/shouldn't; making hypotheses and guessing; the second conditional; adjectives to describe a character; the main features of essays and formal emails; wh-questions; vocabulary to propose solutions; linkers.

- Inter-cultural contents: cultural and social features of a given country; the current situation of bullying in Spain.

- Other contents: creative and critical thinking skills (analysis of the film's cover, summary of a scene, design of a script, analysis of the expression "game over", evaluation of the potential of video games as a solution to bullying, creation of a character); comprehension of emotions; values (respect, tolerance, helping others).

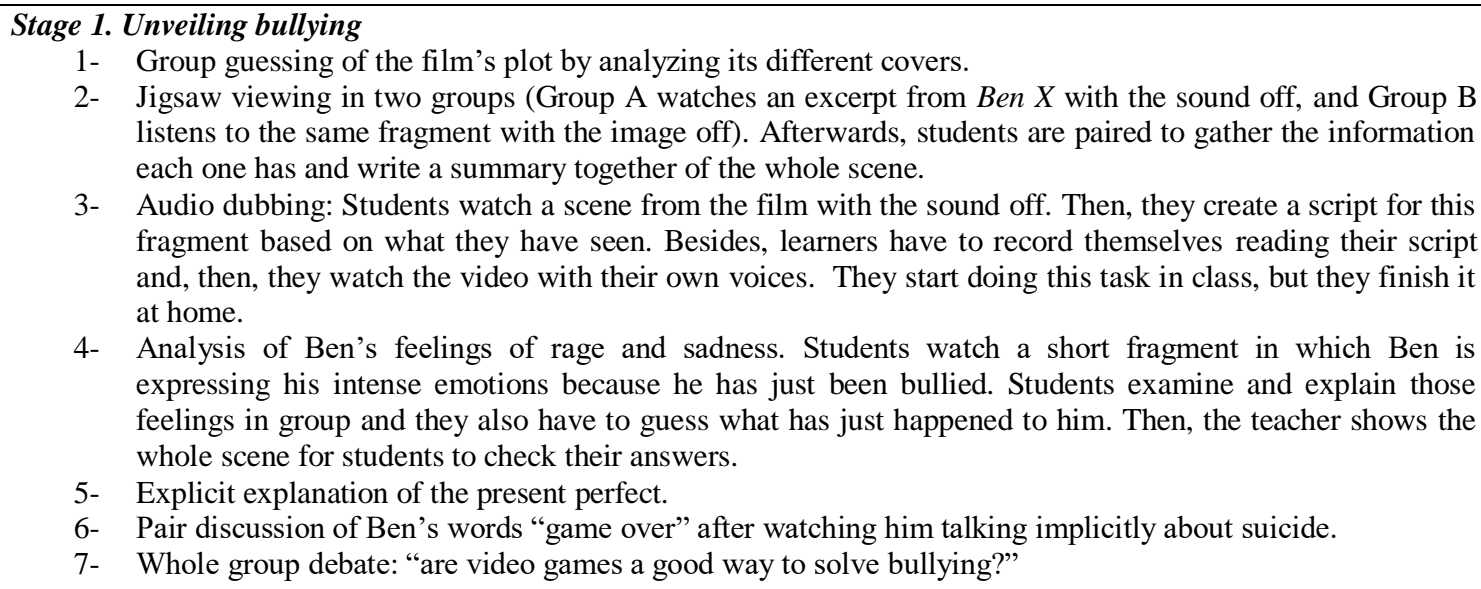

1- Group guessing of the film's plot by analyzing its different covers.

2- Jigsaw viewing in two groups (Group A watches an excerpt from Ben $X$ with the sound off, and Group B listens to the same fragment with the image off). Afterwards, students are paired to gather the information each one has and write a summary together of the whole scene.

3- Audio dubbing: Students watch a scene from the film with the sound off. Then, they create a script for this fragment based on what they have seen. Besides, learners have to record themselves reading their script and, then, they watch the video with their own voices. They start doing this task in class, but they finish it at home.

4- Analysis of Ben's feelings of rage and sadness. Students watch a short fragment in which Ben is expressing his intense emotions because he has just been bullied. Students examine and explain those feelings in group and they also have to guess what has just happened to him. Then, the teacher shows the whole scene for students to check their answers.

5- Explicit explanation of the present perfect.

6- Pair discussion of Ben's words "game over" after watching him talking implicitly about suicide.

7- Whole group debate: "are video games a good way to solve bullying?"

Stage 2. Becoming anti-bullying fighters

1- After watching a scene in which Ben is verbally and physically abused, students create a fictional character who can save Ben online.

2- Oral description and explanation of each student's character. The teacher encourages them to use modals of ability by asking students what their fictional heroes can or can't do.

3- Individual essay in which learners explain how they would save the main character if they could.

4- Thought channel: after watching a fragment from the film in which Ben is thinking about killing himself, one student acts as if s/he was Ben and walks through his/her classmates. They have to give him/her reasons whereby s/he should not kill him/herself.

5- Hot seating: one student sits in front of the classroom and plays the role of one of Ben's bullies. Then, the rest of learners ask him/her questions about such a horrible attitude ("why do you harass Ben?" "What do you get by doing so?" ...)

\section{Stage 3. Dealing with real-life bullying}

1- Group guessing of the setting of Ben X. Students are asked questions such as "where (which country) do you think the film is set?" "what do you know about this country?" ... In pairs they are also asked to compare what they see in the film with the situation of bullying in Spain.

2- Group presentation about bullying in their school, its effects on students, and solutions to that problem.

3- Individual writing of a formal email in which each learner proposes their ideas about how bullying could be prevented in their own high school. They send their formal emails to the teacher. 